\title{
LO ABYECTO VS. LO SAGRADO: LOS SIETE PECADOS CAPITALES Y LA NATURALEZA EN LA CHARCA DE MANUEL ZENO GANDÍA
}

\author{
POR \\ Alessia Dalsant \\ University of New Haven
}

To reign is worth ambition though in hell:

Better to reign in hell than serve in heav'n. John Milton, Paradise Lost [1667], bk. I 1. 262

A lo largo de su vida, Manuel Zeno Gandía demuestra ser un prolífico escritor de diferentes géneros literarios. Como periodista, produce artículos y ensayos críticos sobre autores isleños; también escribe como activista político en defensa del derecho de autodeterminación de Puerto Rico. Su compromiso cívico y político se orienta hacia la liberación de la isla de la herencia colonial, la española primero y, después de 1898, la estadounidense. Si en un primer momento su poesía muestra claras influencias del romanticismo europeo, su prosa se acerca más bien al realismo, hasta adquirir toques naturalistas, especialmente en su tetralogía de novelas Crónicas de un mundo enfermo. ${ }^{1}$ En estas novelas, las diferentes facetas de nuestro autor, el periodista, el literato, el médico y el político, se entremezclan para llevar a cabo un férvido análisis de los males que afectan la isla y también para denunciar las consecuencias del colonialismo.

Además de ser un hombre tan activo en cuestiones prácticas, su vida se caracteriza por un fuerte impulso intelectual y un genuino interés por la cultura, sea esta la contemporánea o la heredada de los antepasados, como por ejemplo la medieval. Este aspecto de su personalidad hace de él un hombre sumamente culto. El hecho de que entre los idiomas que dominaba estaba también el hebreo (Zeno de Matos 45) es índice

\footnotetext{
1 La influencia del naturalismo europeo en Puerto Rico, todavía colonia española hasta 1898, se hace sentir tardíamente. La obra literaria de Émile Zola empieza a circular en Puerto Rico alrededor de 1882. La cuestión naturalista adquiere tonos más intensos ya para 1889, cuando José Arnau publica su serie de artículos titulados "El naturalismo en el arte". A finales de la década de los ochenta, empiezan a publicarse las primeras novelas de tonos naturalistas. De 1887 es La pecadora de Salvador Brau, mientras que Matías González García publica Cosas en 1893 y El escándalo en 1894. En el prólogo de Cosas, González García toma partido con el naturalismo porque ve en él la posibilidad de crear una novela autóctona que declare y analice los males de la sociedad puertorriqueña, ofreciendo así una posibilidad de redención (Álvarez 69-73).
} 
de su propensión a lo erudito. Baste pensar en la importancia de esta lengua, no sólo por ser la empleada en los textos sagrados judíos, sino también por su papel crucial en la España medieval.

$\mathrm{Su}$ actitud conscientemente investigadora se extiende a los asuntos del alma y de la fe, incluyendo el papel social de la religión. Como muchos otros autores de su época, quienes, a pesar de no ser creyentes, miraron a la religión como a un objeto de estudio, Zeno Gandía también se acerca a las cuestiones del culto desde una perspectiva intelectual. ${ }^{3}$ Desde el punto de vista de su fe personal, es difícil establecer si Zeno fuera creyente o menos. Por lo que declara en sus escritos, en particular modo en su poesía parece cierto que no era ni ateo ni agnóstico. Se podría suponer que su postura era más bien deísta, es decir que reconocía la existencia de una entidad superior, un Dios todopoderoso, autor de la naturaleza. ${ }^{4}$ La evidente bipartición entre el mundo abyecto de los seres humanos y el sagrado de la naturaleza que el autor presenta en su novela

2 Los judíos tuvieron un rol fundamental en las escuelas de traducción de Toledo y alfonsí (siglo xII y XIII respectivamente). Desde el siglo x el hebreo, hasta aquel entonces lengua estrictamente litúrgica, se empieza a usar también para escribir versos. Este hecho sienta las bases para el sucesivo florecimiento de la lírica judía (siglo xI). Para más informaciones sobre la lírica medieval en hebreo en España véase Peter Cole, The Dream of the Poem: Hebrew Poetry from Muslim and Christian Spain, 950-1492.

3 Véase por ejemplo al alemán Max Weber (La ética protestante y el espiritu del capitalismo de 1904-05), al francés Émile Durkheim (Las formas elementales de la vida religiosa de 1912) y al estadounidense William James, inventor de la "psicología de la religión" (Las variedades de la experiencia religiosa de 1902)

4 Su soneto “¡Dios es grande!” presenta exactamente este acercamiento a lo divino. En él, Zeno expresa su admiración por esa fuerza creadora, cuya existencia se percibe hasta en sus obras más pequeñas. Según Zeno, la grandeza y el genio de Dios consisten en esto:

Un microscopio que cayó en mi mano

secretos me mostró de luz y vida,

y vi la pequeñez engrandecida

y un nuevo mundo de verdad galano.

$\mathrm{Al}$ advertir tan admirable arcano

el alma en mí pensaba conmovida:

si la grandeza observo enaltecida

de Dios contemplo el genio soberano.

$\mathrm{Y}$ ahora que a favor de clara lente

nueva verdad descubro transparente,

exclamo al conocer la obra del mundo:

"Yo te admiro, Señor del orbe dueño, que si eres en lo grande sin segundo, eres más grande aún en lo pequeño!"

(Zeno Gandía, Poesías 22) más famosa, La charca, confirmaría esta hipótesis. Parece claro entonces que su actitud hacia la religión y sus amplios conocimientos culturales son de fundamental importancia para la representación de los vicios que afectan la sociedad campesina puertorriqueña descrita en dicha obra.

Publicada en 1894, La charca es la primera de cuatro novelas que Zeno agrupa bajo el subtítulo Crónicas de un mundo enfermo. En esta tetralogía el autor se propone representar las diferentes facetas de la realidad puertorriqueña. Si en La charca Zeno Gandía hace un cuadro de la vida de los campesinos en las fincas de café, en Garduña, de 1896, describe la situación en los cañaverales. A estas dos novelas, siguen dos más que trasladan la acción al área urbana: El negocio, de 1922, se centra en la vida comercial y en Redentores de 1925, en la vida política en Puerto Rico. La intención de Zeno Gandía, explícita en el subtítulo de estas novelas, es la de ofrecer una visión médico-científica de la sociedad puertorriqueña, abarcando todas las clases sociales y consecuentemente, todas la posibles "enfermedades" que la afectan.

Durante sus estancias en Europa, Zeno Gandía entra en contacto con los naturalistas y los poetas parnasianos franceses. ${ }^{5}$ Además, su oficio de médico lo acerca a la figura de Claudio Bernard que tanto había inspirado a Zola y, al mismo tiempo, a uno de los personajes del mismo novelista francés, el doctor Pascal. No sería una casualidad entonces que Zeno escogiese como inscripción de La charca, una cita sacada de $E l$ doctor Pascal (1893), novela que pertenece al ciclo de Rougon Macquart: "Decirlo todo para conocerlo todo, para curarlo todo: tal era el grito que había proferido en la serena noche de verano". ${ }^{6}$ Con esta cita no sólo declara su intento de escribir novelas al estilo naturalista, sino también pone de relieve la función terapéutica y didáctica de acto de contar. Tal hecho se confirma también por la siguiente declaración del mismo autor: "Es necesario, [...] perseguir las evoluciones de los átomos con el microscopio y

En 1871 irrumpe en Francia la corriente literaria llamada naturalismo. Su máximo exponente, Émile Zola, propone extender el espíritu científico del siglo a la literatura; por consiguiente, crea un tipo de novela que pretende elucidar la realidad social mediante la aplicación de métodos científicos. "Como Claudio Bernard, que luchó por hacer de la medicina una ciencia, en lugar de un arte como hasta en su época se la consideraba, Zola creará la novela experimental" (Guzmán 155). Además de ser médico, el escritor naturalista estudia el comportamiento del hombre en su preciso contexto social, con la intención de llegar a conocito Una vez determinadas las causas de los males que afectan la sociedd, el novelista ofrecerá su cura para sanarla. Para llevar a cabo esta tarea, Zola cree firmemente en un estilo objetivo, imparcial, científico y falto de todo lirismo, lo cual le permitiría crear una novela que, no obstante choque al lector por sus escenas terribles, escandalosas e inmorales, produzca una verdad incuestionable. De aquí nace la estética del feísmo, tan representativa de esta corriente literaria, según la cual la ética no debe coincidir con la estética. Gracias a este estudio imparcial, los naturalistas denuncian los crímenes sociales y la necesidad de reformas para sanar la sociedad.

6 Todas las citas sacadas de la novela se refieren a la siguiente edición: Manuel Zeno Gandía, La charca (Río Piedras: Ediciones Huracán, 1999). 36.
Revista Iberoamericana, Vol. LXXIX, Núms. 244-245, Julio-Diciembre 2013, 797-816 ISSN 0034-9631 (Impreso)
Revista Iberoamericana, Vol. LXXIX, Núms. 244-245, Julio-Diciembre 2013, 797-816 ISSN 0034-9631 (Impreso) 
el telescopio y el reactivo; hay que analizar las tempestades del alma dentro de la moral y la filosofía y las artes con el naturalismo"” (Rivera de Álvarez 1634).

Aunque su propósito es abiertamente naturalista, Zeno Gandía reinterpreta este movimiento literario según su conciencia ética y lo adapta a la sociedad puertorriqueña que representa en $\mathrm{La}$ charca. ${ }^{7}$ Zeno Gandía mezcla el rigor del objetivismo descriptivo zoliano con el propósito moralizante de llevar a cabo una denuncia de los males que afectan su isla. Este "naturalismo matizado" logra de igual manera impactar a su público, especialmente gracias a la constante tensión en la novela entre los elementos abyectos y los sagrados. En contraste con el naturalismo de Zola que buscaba la verdad absoluta la ley perfecta que proporcionara la solución a los males de la sociedad, ${ }^{8}$ en $L a$ charca Zeno Gandía toma una posición más ambigua y crítica. ${ }^{9}$ En la narración mezcla lo subjetivo con lo objetivo, el cientificismo descriptivo con las perspectivas del narrado y a menudo hasta emplea un estilo sumamente lírico, especialmente con respecto a las descripciones de la naturaleza. Zeno Gandía alterna cuadros de la sórdida realidad puertorriqueña a un fuerte lirismo descriptivo del paisaje isleño. De tal manera, mediante la contraposición de la sociedad enferma al paradisiaco paisaje natural, la representación

Los estudios de Guillermo Ara (1965) y de Manuel Prendes (2003) que llevan el mismo título, La novela naturalista hispanoamericana, son dos referencias imprescindibles para cualquier aproximación a naturalismo hispanoamericano.

8 En muchos de sus ensayos críticos, Zola explica su idea de naturalismo y del papel del artista. En "Le Naturalisme au théâtre", afirma que el artista debe ser "simplement un observateur qui constate des faits" ("simplemente un observador que constata los hechos"; 110). Según Zolu, la observación directa de la à la nature et à l'homme, l'observation directe, l'anatomie exacte, l'acceptation et la peinture de ce qui est. [...] Il s'agissait de tout recommencer, de connaitre l'homme aux sources mêmes de son être, [... et les écrivains n'avaient désormais qu'à reprendre l'édifice par la base, en apportant le plus possible de documents humains, présentés dans leur ordre logique." ("El naturalismo en las letras es, igualmente, la vuelta a la naturaleza y al hombre, es la observación directa, la anatomía exacta, la aceptación y la descripción exacta de lo que existe. [...] Hacía falta comenzarlo todo de nuevo y conocer las misma raíces del ser del hombre, [...] y los escritores sólo debían retomar el edificio por las bases, juntando el mayor número posible de documentos humanos, presentados en su orden lógico"; 114-115). La traducciones del francés son mís. Para las ideas de Émile Zola sobre el naturalismo, véase su colección le ensaros tithada Le Roman expérimental. Sobre el papel del artista y de su espíitu de observación, véase el interesante artículo de William J. Berg "A Poetic of Wision: Zola's Theory ar la estética del naturalismo, véase Anthony Savile "Natur

9 A causa de la tardía independencia de la zona caribeña con respecto al resto de Hispanoamérica, el naturalismo en Puerto Rico se centra en una fuerte crítica a la herencia del colonialismo y la explotación de los seres más débiles. Manuel Zeno Gandía se ubica entonces entre los naturalistas hispanoamericano socia o políticamente comprometidos. Sin embargo, al mismo tiempo el médico puertorriqueño se distancia de ellos por su cuestionamiento de los postulados naturalistas. Sobre la posición de Zeno Gandía frente a la corriente naturalista, remito al interesante ensayo de Aníbal González "La caída de Silvina: naturalismo y ética de la escritura en La charca (1894) de Manuel Zeno Gandía".

Revista Iberoamericana, Vol. LXXIX, Núms. 244-245, Julio-Diciembre 2013, 797-816 ISSN 0034-9631 (Impreso) ISSN 2154-4794 (Electrónico) de la mezquindad humana resulta aún más impactante.

A una primera lectura de la novela llama mucho la atención la indudable partición en dos mundos que si bien coexisten, compartiendo el mismo espacio geográfico y el mismo principio creador, se contraponen por sus características contrastantes. Parte de propósito del presente trabajo es entonces el de analizar esta oposición en términos de la ausencia de Dios en la vida de los protagonistas de La charca (lo abyecto), frente a la existencia de un elemento divino, numinoso, en el mundo natural (lo sagrado). ${ }^{10}$ Mediante esta contraposición, Zeno Gandía quiere mostrar a sus lectores el estado bestial de la vida de los campesinos, cuyos vicios se encajan en la simbología mítica de los siete pecados capitales. El autor sustituye al Dios que regula las relaciones humanas por una serie de vicios, personificados por los protagonistas de La charca. Así, encontramos a personajes que simbolizan la avaricia, la lujuria, la pereza, la soberbia, la gula, la ira, la envidia y la codicia.

De la misma manera que un médico, Zeno Gandía diagnóstica los males que afectan la sociedad puertorriqueña, pero no consigue encontrar una solución que remedie a tales problemas. Además, dentro del argumento de la novela, cada esfuerzo para lograr la verdad y la justicia fracasa, mientras que los personajes que tienen éxito y se salvan son precisamente los más abyectos. Esta ambigüedad y oscilación del tono y contenido ofrecen una crítica del mismo naturalismo y a sus pretensiones científicas. Como sostiene Aníbal González "Si hubiese que caracterizar La charca sintéticamente, en una sola frase, podríamos decir que es 'la novela de la duda'. La charca es un texto hipercrítico, de múltiples niveles que se cuestionan, parodian e interfieren mutuamente sin arrojar un saldo positivo de conocimiento" (82).

En efecto, las teorias propuestas por cada uno de los "falsos redentores" para mejorar la vida de los isleños se hunden bajo la categórica afirmación del doctor Pintado: "Esta generación no se salva: está perdida [...]" (La charca 223). Como se verá al final de

\footnotetext{
${ }^{10}$ En general, el aspecto de la religión en el movimiento naturalista no ha sido muy estudiado. La crítica de Émile Zola se ha ocupado de este tema de manera sumaria. Vale la pena mencionar cuatro estudios: 1Guillemin Henri, Zola, Légende ou véritée; 2-René-Pierre Colin, Zola Renégats et alliés. La République naturaliste; 3-Pierre Ouvrard, Zola et le prêtre; 4-Jean Borie, Zola et les Mythes ou de la nauseé au salut. Con respecto a Españ e Hispanoamérica, no existe un estudio que abarque de manera explícita com Con te escuela francesa, la postura de los autores espanoles e hispanoamericanos no ellmina por completo que el francés. En efecto, es nota la postura de la condesa Emilia de Pardo Bazán, quien, en el libro $L a$ cuestión palpitante, defiende la salvaguardia de la dimensión espiritual del hombre en dicha corriente literaria (150-151). Para la recepción del naturalismo por parte de la iglesia católica en España, véase Solange Hibbs-Lissorgues "La iglesia católica y el naturalismo". Con respecto a la literatura anticlerical, véase el capítulo V de Anticlericalismo y literatura en ele siglo XIX por José Luis Molina Martínez. En la literatura hispanoamericana, la cuestión de la religión y el naturalismo ha sido explorada aún menos y un estudio serio queda por hacer.
}

27. Revista Iberoamericana, Vol. LXXIX, Núms. 244-245, Julio-Diciembre 2013, 797-816 ISSN 0034-9631 (Impreso) ISSN 2154-4794 (Electrónico) 
la novela, la persistencia de los campesinos en vivir de acuerdo con los siete pecados capitales y su falta de voluntad en corregir su comportamiento dañino les perjudica cualquier posibilidad de salvación. Ésta depende únicamente del individuo y de su fuerza de voluntad; en el caso de los protagonistas de La charca, o falta por completo o se percibe como explotación del prójimo y de los más débiles. Por eso, la función de la naturaleza es la de recordarles a los puertorriqueños de que existe una dimensión sagrada y que en ella hay que buscar refugio. La muerte más que salvación es una liberación de las penas que el cuerpo sufre en la vida terrenal. Los puertorriqueños reviven el mismo pecado de Adán y Eva: habitan un lugar paradisíaco pero su codicia los empuja a pecar de manera desmesurada. Por eso, caen en una especie de desarmonía con el mundo natural, que empiezan a percibir en puros términos utilitarios. En La charca, Zeno Gandía presenta la tensión provocada por la convivencia de una sociedad que se rige por los siete pecados capitales y un medio ambiente que recuerda constantemente lo sagrado. Es preciso entonces, profundizar un poco más acerca del concepto de pecado capital.

En primer lugar, hay que distinguir entre el concepto de vicio y el de pecado. Si la palabra vicio define un aspecto de la personalidad de un individuo, el pecado simboliza más bien un acto concreto que va en contra de una serie de reglas convencionalmente aceptadas. Según Solomon Schimmel el concepto de vicio y de virtud se acocia a la filosofía moral grecorromana, mientras que la idea de pecado pertenece a la tradición judeocristiana. En el momento en que el judeocristianismo asimilan la herencia grecorromana, vicio y pecado se vuelven dos conceptos intercambiables, casi como si fueran sinónimos (14). Se puede entonces decir que los siete pecados capitales coinciden con una serie de actitudes negativas que caracterizan y afectan a todos los seres humanos. ${ }^{1}$

En la religión cristiana, se habla del pecado como de un acto ilícito, una conducta considerada reprobable o ilegítima, en contraste con los principios y las normas morales reconocidas en el ámbito de una sociedad. ${ }^{12}$ El concepto de pecado se vincula de manera

${ }_{11}$ Las sociedades arriba mencionadas conferían un valor sagrado al número siete. En efecto, era práctica La del mundo en siete días, las sietes velas del candelabro judío, los siete animales (por cada especie) que Noé llevó en su arca, etc.

${ }^{12}$ Se ofrece aquí un breve resumen de cómo la idea de los siete pecados capitales evoluciona durante la Edad Media. Según el estudioso Morton W. Bloomfield, el monje Evagrius Ponticus (400) fue el primer escritor cristiano quien nombró (en griego) los pecados cardinales, identificando ocho de ellos (gula, avaritia, luxuria, superbia, ira, tristitia, vanagloria y acedia). Más tarde, su estudiante Joannus Cassianus (ca 360-435) tradujo esta lista al latín, introduciendo así los vicios capitales en la cristiandad europea. Durante el sexto siglo, papa Gregorio I redujo el número de pecados de ocho a siete, juntando tristitia con acedia, vanagloria con superbia y añadiendo la envidia. En su Divina Commedia, Dante Alighier usa esta misma lista de pecados. Desde aquel entonces, los vicios capitales se establecen con el número de siete, según los dictémenes de Gregorio. Durante la Edad Medie se va articulundo la idea de vicio

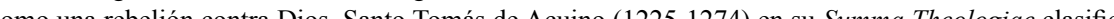
los siete pecados capitales como hoy los conocemos: la soberbia, la avaricia, la lujuria, la ira, la gula, estrecha al de la ley de Dios, revelada y conservada en los Textos Sagrados; por eso, pecar representa una transgresión de estas normas y, por lo menos inicialmente, una rebelión contra Dios. Esta transgresión no coincide sólo con el acto de quebrantar la ley, sino también con la falta de acción, lo que se omite hacer para que se respete. Entonces, el pecado constituye un acto conciente y responsable, ejecutado voluntariamente por la criatura humana, ya sea por comisión u omisión. Además de constituir una desviación de la norma, el concepto de vicio está sumamente relacionado al de lo abyecto. Como dice Julia Kristeva en Powers of Horror, "It is thus not lack of cleanliness or health that causes abjection but what disturbs identity, system, order. What does not respect borders, positions, rules" (4). De tal manera, se deduce que el pecado consiste de un acto inmoral, mediante el cual el hombre, de acuerdo con su libre albedrío, rompe la ley divina que dicta la conducta moral apropiada.

A lo largo de la historia, la idea de pecado va adquiriendo significados diferentes. El filósofo italiano Umberto Galimberti explica que el Siglo de las Luces presenta una perspectiva más laica y utilitarista de los vicios capitales. En este período se empieza a considerar los factores determinantes que contribuyen activamente al desarrollo social, económico e industrial de los paises modernos. ${ }^{13}$ Según Galimberti, es a partir de Immanuel Kant (1724-1804) que se empieza a concebir el vicio como una manifestación de diferentes tipologías humanas y no sólo como una desviación moral. Su obra, Antropología pragmática (1798), sirve de base para muchos estudiosos de psicología y del subconciente humano, como por ejemplo Sigmund Freud. Ya no se perciben los vicios capitales como una rebelión contra Dios, ni como propulsores del capitalismo, sino como una patología del hombre, una enfermedad de su espíritu.

la envidia y la pereza. Según el filósofo español Fernando Savater los siete pecados capitales servían como admonición para que el hombre medieval se diese cuenta del peligro de los excesos y escogiese así una conducta más moderada. Su función era entonces la de indicar al ser humano los comportamientos que debía evitar. De tal manera, las siete virtudes cardinales, la humildad, la generosidad, la castidad, la paciencia, la templanza, la caridad y la diligencia, venían a definir los modelos de conducta hacia los cuales la sociedad cristiana medieval debía aspirar.

Para aclarar esta idea, Galimberti trae a colacion un poema titulado The Fable of the Bees. Private Vices. Public Benefits, escrito en 1705 por el londinés Bernard de Mandeville. Según Mandeville, los vicio nacen del deseo y de la necesidad de satisfacerlo. Si pensamos que la función de la sociedad corresponde esencialmente con la de satisfacer las exigencias del ser humano, podemos deducir que los vicios mejoran la economí porque amontan las necesidales del ser huma. Consecontem los cono los cons

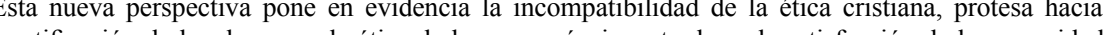
mortificación de los deseos, y la ética de la economía, incentrada en la satisfacción de las necesidades. Según la moral cristiana la virtud implica una renuncia al lujo y al exceso y por eso, dice Mandeville, no beneficia ni al individuo ni a la comunidad. De manera contraria, el vicio estimula la circulación de biene materiales y de consumo, lo cual aumenta el capital.

Revista Iberoamericana, Vol. LXXIX, Núms. 244-245, Julio-Diciembre 2013, 797-816 ISSN 0034-9631 (Impreso)

(it) ISSN 2154-4794 (Electrónico)
Revista Iberoamericana, Vol. LXXIX, Núms. 244-245, Julio-Diciembre 2013, 797-816 ISSN 0034-9631 (Impreso) ISSN 2154-4794 (Electrónico) 
En La charca, Manuel Zeno Gandía insiste en presentar la comunidad de campesinos como una sociedad enferma y dominada por los vicios. Dado su oficio de médico que lo lleva a conocer las zonas rurales de la isla, su activismo político profeso a mejorar la situación de su país, su compromiso social en denunciar los males que afectan la sociedad puertorriqueña, y su curiosidad intelectual que le permite desarrollar una gran cultura, el recurso a la simbología mítica de los siete pecados capitales no parece sorprendente. Como médico y observador de primera mano de las deficencias que sufre su isla, Zeno Gandía ve las enfermedades físicas y espirituales de su gente y las representa en su novela. La denuncia que lleva a cabo es, sin embargo, extremadamente escéptica en particular por lo que concierne la posibilidad de resolver la situación. En La charca, muchos de los personajes, tanto ricos como pobres, rechazan cambiar el estado de las cosas y prefieren dejar que todo siga igual en la corrupción más total.

En contraste a las novelas naturalistas francesas, en las cuales la vida de lo personajes está manipulada por el determinismo social y ambiental, en La charca Zeno Gandía deja que sus protagonistas actúen siguiendo su propia voluntad y, como se verá, escogen la vía del pecado en vez de un camino más recto. Es cierto que parte de la razón por la cual la masa de campesinos no consigue mejorar su situación se debe a su propia ignorancia, como también a su herencia cultural. Éstas les impiden encontrar una alternativa de conducta a su existencia cotidiana y una salida de sus miserias. Sin embargo, en el momento en que se les ofrece una oportunidad de salir de este letal torbellino (véase cuando Silvina tiene la posibilidad de escaparse con Ciro), los personajes se dejan vencer por una especie de "pereza existencial" que los paraliza y mantiene en la charca en la que viven. La reiteración de comportamientos viciosos crea una costumbre, un hábito que, si no se corrige, se transforma en una enfermedad del espíritu. El autor pretende entonces proporcionar una crítica a la degeneración de la sociedad puertorriqueña de su tiempo; por eso, representa una comunidad sórdida cuya existencia se funda en la satisfacción de deseos bajos y de los vicios capitales: la ira (también vista como venganza), la soberbia, la codicia, la lujuria, la envidia, la pereza y la gula (el consumo excesivo de bebida o comida).

En su interesante ensayo "Language and Space: from Oedipus to Zola", Michael Serres sostiene que detrás del cientificismo del novelista francés se esconden residuos de la mitología grecolatina o judeocristiana: "Suddenly science falls silent and mythology speaks [...] And thus this global result: once the scientific contents are filtered out, a residue remains in which a circulational game organizes reformulations of mythica material” (41-42). Zeno Gandía, como Zola, recurre a la mitología judeocristiana para expresar y reforzar su visión de la realidad puertorriqueña; el uso de un estilo meramente científico no le permitiría presentarnos un cuadro suficientemente convincente para que él pueda llevar a cabo su denuncia social. Por eso, la resonancia de los mitos, sean en este caso los siete pecados capitales o el fratricidio de Abel por Caín (véase cuando Marcelo ISSN 0034-9631 (Impreso)

Vol. LXXIX, Núms. 244-245, Julio-Diciembre 2013, 797-816 ISSN 2154-4794 (Electrónico) mata a Ciro bajo los efectos de la envidia, de la gula y del alcohol), ofrece al novelista la posibilidad de trabajar las verdades heredadas por la tradición, que establecen los valores y los significados de la vida humana.

En La charca el autor describe la vida de una comunidad de campesinos situada en la zona montañosa de Puerto Rico. Entre ellos se encuentran: los terratenientes Juan del Salto y Galante, el tendero Andújar con su primo Deblás (quien es un refugiado escapado de la prisión), el mayordomo Montesa y los campesinos Gaspar, Silvina, su madre Leandra, los hermanos Ciro y Marcelo y la vieja Marta. Dentro de esta multitud de personajes, resulta difícil identificar a un protagonista principal ya que a lo largo de la novela sus vicisitudes se entrelazan poniéndolos a todos en contacto más o menos directo.

Las primeras páginas del capítulo inicial, presentan las relaciones entre Silvina, Leandra, Gaspar y Galante, poniendo en claro de una vez el carácter perverso y lujurioso de éstas. Para asegurarse la protección del rico Galante, Leandra acepta el "tráfico inicuo" que éste le propone y le entrega el cuerpo de su hija Silvina, joven de catorce años, a quien además obliga a casarse con el muy grosero Gaspar, hombre mucho mayor que ella. Todos juntos viven en la choza de Leandra y, en una noche de lluvia, Galante consigue satisfacer sus deseos lujuriosos:

Una noche en que llovía torrencialmente, la casucha se anegó. La familia tuvo que reunirse toda en uno de los dos únicos cuartuchos de la casa. El sueño en común acortó las distancias, y Silvina, sorprendida, cuando, no bien despierta, quiso luchar, oyó la voz de Leandra que le decía al oído: -Hija, no seas tonta ..., no seas tú la causa de que nos muramos de hambre. Y Galante, bajo las sombras, al fulgor de los relámpagos, derribó a la virgen. (42)

No sólo la lujuria empuja a Galante a tener relaciones con más de una mujer, sino también con la hija de su propia compañera “oficial”. Además de esto, choca la pereza de Leandra que prefiere hacerse mantener por Galante barateando a su progenie en cambio de una mediocre estabilidad económica ofrecida por él y por Gaspar. Como leemos en la novela, estos hombres no mejoran la vida de las dos mujeres, quienes siguen padeciendo el hambre y además pierden su libertad, volviéndose sirvientas y esclavas sexuales.

En otro episodio somos testigos de este pecado junto al de la avaricia, el deseo desenfrenado de poseer bienes materiales. Me refiero a Galante y a su homicidio de Ginés, "[...] un modesto propietario cuyos terrenos colindaban con los de Galante. Ginés, que era joven, vivía con Aurelia, su esposa, una de las campesinas más bellas de la comarca" (62). Mediante el recuento de Marcelo, testigo de la escena, el lector se entera de que una noche, Galante mata a Ginés tirándole una piedra atada a una cuerda desde un árbol; sucesivamente, arroja el cuerpo por la vertiente. Poco tiempo después, Galante empieza a hacer visitas a la viuda Aurelia, a mantenerla y hasta llega a comprarle los terrenos pagándoselos en "provisiones y mercancías”. Al final: "Como
Revista Iberoamericana, Vol. LXXIX, Núms. 244-245, Julio-Diciembre 2013, 797-816 ISSN 0034-9631 (Impreso) 
Galante era dueño de la finca, echó al camino a Aurelia. Ella se fue en busca de unos parientes, llevándose un niño, hijo de Galante, que éste no quiso reconocer [...]" (6667). El cálculo, la codicia y la lujuria son los únicos ídolos que mueven a este ínfimo personaje, que con sus actos disemina muerte y corrupción.

Las motivaciones del episodio central de la novela, el asesinato de Deblás, coinciden con la codicia, la envidia, la ira, la soberbia, la pereza y la gula. Deblás, refugiado en casa de su primo Andújar por haber escapado de la cárcel después de haber matado a un hombre por dinero, planifica con el codicioso y cobarde Gaspar, el homicidio del tendero para robarle el tesoro que tiene escondido en su tienda. Gaspar propone llevarse a Silvina para asegurarse de que calle y no revele el secreto. Sin embargo, Marcelo, quien había escuchado una conversación privada de los dos ladrones, revela sus planes a Andújar, quien, en la noche establecida para el robo, desaparece llevándose su tesoro. Al encontra la tienda vacía, Deblás advierte a Gaspar que vuelva a su casa. Luego, guiado por la codicia Deblás regresa a rebuscar la tienda para asegurarse que no haya quedado nada. Fuertemente irritado por el fracaso del plan, trata de vengarse comiendo y bebiendo todo lo que encuentra, pecando así de gula e ira a la vez. "Engullía nerviosamente grandes bocados que tragaba casi sin masticarlos. Hubiera querido tener un apetito de diez años de abstinencia para poderse aprovechar, para consumir la mayor cantidad posible de subsistencias y así fastidiar a su primo, castigándole por haberse llevado el codiciado talego"(170). Al final se emborracha y, empujado por las necesidades del cuerpo, se queda dormido en el catre de Andújar.

Mientras tanto, Gaspar decide volver a la tienda junto a Silvina empujado por las mismas intenciones de Deblás: "sobraba impulsado por un alarde de valor y de codicia: si el dinero estaba allí sería para él solo, si no estaba no había peligro en penetrar, porque el tendero no regresaría hasta el día siguiente. Sin embargo del esfuerzo, a duras penas dominaba el miedo" (174). Al darse cuenta de que alguien está durmiendo y al creer que éste sea Andújar, Gaspar agarra la mano de Silvina y descarga una cuchillada morta que mata al mal encontrado Deblás. El episodio termina con Gaspar que, reconocida la víctima, exclama aterrorizado: “¡Condenación del infierno!... ¡He matado a Dedlás!” (177) y escapa "[...] con los ojos espantados y profiriendo horribles imprecaciones, atroces maldiciones, injurias sacrílegas al cielo, a la tierra, al infierno y a Dios" (177) Con estas imprecaciones, Zeno enfatiza la soberbia y la ira de Gaspar que, a pesar del acto sórdido que acaba de cumplir, desahoga su cólera con palabras altivas e injuriosas hacia Dios. Además, el autor muestra que la codicia lleva a los personajes a actuar de manera incontrolada y a causar hasta la muerte.

A lo largo de la novela, Zeno hace frecuentes menciones al problema de la gula y de la pereza en la comunidad de campesinos. Desde el comienzo, Leandra se queja de la mala costumbre de los hombres de tomar, gastando así tiempo y dinero en la tienda de Andújar en vez de sustentar sus familias. También Juan del Salto critica el consumo de esta bebida letal que transforma los hombres en seres violentos. El personaje de Marcelo muestra las consecuencias y los peligros del alcohol. Durante un largo viaje al pueblo para intercambiar mercancías, Marcelo se siente sin fuerzas, debido al hambre y la anemia. Como es abstemio, rehúsa tomar alcohol durante el camino, pero sus compañeros de viaje se burlan de él. Empujado por la envidia del vigor de los demás, al final cede y empieza a beber: "Marcelo, con la cabeza baja y meditando silencioso, dejábase llevar por su mulo. Hubiera querido ser como los otros, que hacían de todo sin que les pasara nada. Por allí iban tan alegres, tan contentos, sintiéndose fuertes y felices alimentados con aquellos tragos sorbidos a purso" (242-3). El resultado es desastroso: Marcelo toma de manera exagerada y si bien al principio se vuelve el bufón de la compañía, al final termina por fastidiar a todos. "El veneno alcohólico, obrando en él lentamente, produjo con disimulo su desastre: fuese elaborando poco a poco la perturbación hasta dispararle con fiereza en el ímpetu" (246). El abuso del licor causa una riña con su hermano Ciro y Marcelo termina por darle una cuchillada mortal en el corazón. ${ }^{14}$

Un personaje en particular representa el pecado de la avaricia, la vieja Marta. Propietaria de una pequeña plantación de café, la vieja Marta vive de limosna tratando de acumular a escondidas todas las riquezas posibles y ostentando una vida de pobreza. "Su avaricia era sórdida, anhelosa, capaz de llegar al crimen" (76). En efecto, se anticipa aquí la tragedia que ocurrirá hacia el final de la novela. Marta vive con su nieto, “[...] un niño de catorce años, de tan atrasado desarrollo, que parecía no rebasar de los seis. La buena abuela le mataba de hambre; cuando se es pobre, es menester acostumbrarse a la necesidad, porque dondequiera está Dios" (76). Marta no se refiere aquí al Dios caritativo que ve y provee al bienestar de sus ovejas. Su Dios coincide más bien con cualquier "piltrafa", cualquier limosna recibida u objeto encontrado que le pueda proporcionar ahorro y ganancia. Con esta filosofía enfocada en la avaricia, Marta llega a desnutrir tanto a su nieto que lo reduce a un esqueleto viviente. Su muerte en el capitulo diez, está descrita por Zeno Gandía como una liberación de los abusos de la vieja, un pasar a mejor vida que asegurará a esta víctima indefensa más dicha de la que experimentó en su vida terrenal. "Rindióse el cuerpecillo en el polvo y el espíritu voló muy lejos, donde Dios le llamara, donde hubiera ventura bastante para compensar los dolores de su tránsito por la vida" $(232) .{ }^{15}$

${ }^{14}$ Mediante el final dramático de esta escena, Zeno vuelve a los mitos, a la tradición judeocristiana, a fratricidio de Abel por mano de Caín. Se repite la historia del antiguo testamento y la desgracia que el pecado de la envidia provoca.

15 Si la vieja Marta es con una personificación de la avaricia entre los campesinos, entre los ricos Juan del Salto y Galante persiguen el acaparamiento de recursos naturales. Los isleños no perciben la naturaleza Salto y Galante persiguen el acaparamiento de recursos naturales. Los isleños no perciben la naturaleza
como un don divino con el cual se debe vivir en armonía; su existencia se reduce a pura materialidad en función de la explotación de la tierra y la producción de capital.

Revista Iberoamericana, Vol. LXXIX, Núms. 244-245, Julio-Diciembre 2013, 797-816 ISSN 0034-9631 (Impreso) LXXIX, Núms. 244-245, Julio-Diciembre 2013, 797-816
ISSN 2154-4794 (Electrónico)
Revista Iberoamericana, Vol. LXXIX, Núms. 244-245, Julio-Diciembre 2013, 797-816 ISSN 0034-9631 (Impreso) 
En el mundo de los seres humanos presentado por Zeno Gandía en La charca, la palabra Dios aparece como exclamación, imprecación, en refranes, o como promesa de felicidad en otro mundo, pero este ser supremo nunca parece estar presente entre los hombres. También cuando el sacerdote Esteban habla de la religión lo hace en términos teóricos y jamás actúa de manera concreta para ejemplificar tales especulaciones. En la novela, faltan por completo escenas de culto colectivo o de rituales religiosos; nunca vemos a los campesinos rezar. Es un mundo sin Dios, y no podría ser de otra forma, dado que los isleños han escogido la vía de los siete pecados capitales.

En el capitulo dos, Zeno introduce al terrateniente Juan del Salto, quien encarna la tensión existente entre lo sagrado y lo abyecto, la lucha entre un idealismo optimista y un pragmatismo pesimista. En efecto, desde las primeras páginas vemos a Juan actuar como si fuera un "buen pastor", que guía sus ovejas hacia la recta vía aconsejándoles y tratando de levantarlos de su propia miseria y pereza. "Era para él un ideal: rehacer aquel conjunto de seres; prepararlos para risueño porvenir; hacer hombres para que se defendieran del látigo; dar ciudadanía a la plebe; hacer hombres fuertes, capaces de resistir en lo físico y en lo moral, en el individuo y en la especie, la acción depriment de las causas mórbidas" (50). Parece que Juan del Salto se transforma en un pequeño demiurgo, cuyas especulaciones filosóficas se mezclan a las teorías de Darwin para dirigirse a mejorar la raza. Mediante este personaje, Zeno Gandía demuestra la preocupación por su país: evidencia la división entre alma y cuerpo y cómo este último gobierna el primero; cuestiona cuáles sean los verdaderos intereses de esta sociedad y prevé un porvenir aún más degenerado a menos que las cosas no cambien. Sin embargo, como se ve en el capítulo nueve, el autor mismo desmiente la posibilidad de que los representantes de este grupo social quieran verdaderamente actuar como redentores. En efecto, los proyectos de salvar a la sociedad puertorriqueña de Juan del Salto, de sacerdote Esteban y del doctor Pintado, nunca llegan a concretizarse y ceden el paso a su egoísmo e interés personal.

Una reunión en casa de Juan ofrece a los tres protagonistas la ocasión de discutir os problemas que afligen a los campesinos. El debate ocurre esencialmente entre Esteban y Pintado, mientras que Juan del Salto mantiene un papel de mediador entre los dos e interviene sólo al final. Las posiciones del sacerdote y del doctor parecen ser diametralmente opuestas, pero en concreto, ambos ofrecen remedios muy teóricos y demasiado abstractos para que se opere un verdadero cambio. A pesar de su óptica científica, ninguno de los tres (Juan incluido) lucha activamente para destruir los males que afectan a la sociedad puertorriqueña. Esteban denuncia la falta de Dios y declara la necesidad de cuidar el cuerpo y el alma a la vez para enseñar la vía moral. Sin embargo, la solución que ofrece coincide con la mera predicación del culto y con la imposición de la ley divina, y no con una verdadera comunión entre seres humanos y Dios. La religión según Esteban equivale a una fórmula matemática, a una ecuación vacía, privada de cualquier fundamento espiritual: ISSN 0034-9631 (Impreso) ISSN 2154-4794 (Electrónico)
Mas entiéndase que la religión-ciencia es eminentemente práctica. Véanse los Mandamientos de la ley de Dios, por ejemplo...; pues su infracción acarrea trastornos físicos, intelectuales, morales y, por ende, sociales. La religión es al progreso lo que el principio vital a los organismos. Llénese de alimentos el estómago de un cadáver: no habrá digestión; quítese la vida a un ser pensante: no habrá progreso. Y la vida viene de Dios..., luego Dios es progreso... (225)

Zeno parece proporcionar una fuerte crítica a la falta de espiritualidad en la filosofía religiosa de Esteban. Sus principios son correctos (por ejemplo, la infracción de los mandamientos causa desorden social), pero la fórmula que deriva está muy lejos de una religiosidad pura, vivida por medio de la fe.

En la novela, el doctor Pintado representa la perspectiva materialista, positivista y darwinista. Según él, la gente debe estar física e intelectualmente dispuesta a recibir la "semilla moral", cosa imposible para este grupo social que él considera inferior. De tal manera, el remedio que ofrece consiste en el avance económico y en la producción de riquezas materiales: "Todo a valor positivo se reducía; todo cristalizaba en oro; todo cuajaba en riquezas materiales. Lo que no obedeciere a tal regla, que se arrumbase. ¿Queríanse sociedades cultas y libres?..., pues dinero, dinero y dinero" (225). Por otro lado, Juan del Salto propone la libertad como agente resolutorio y motor del progreso. Más al final, estos nobles intentos de mejorar el destino de la raza puertorriqueña se hunden bajo instintos egocéntricos: Esteban piensa en el ritual que debe desempeñar al día siguiente; Pintado reflexiona sobre la inutilidad de su visita al moribundo nieto de Marta; Juan del Salto calcula la cosecha del día, lo que probablemente ganará de ella, y piensa en su hijo Jacobo. Con este final de capítulo, Zeno Gandía declara que, a causa de la inactividad de los tres "falsos redentores", la sociedad puertorriqueña no puede progresar y queda paralizada en la "charca" de su miserable estado.

Frente a la inmoralidad y a los egoísmos libremente escogidos por el ser humano, Zeno Gandía contrapone la amoralidad de la naturaleza, que generalmente se manifiesta mediante su impotencia hacia las decadentes conductas de los carnífices y hacia las tragedias de las víctimas. Kristeva sostiene que,

He who denies morality is not abject; there can be grandeur in amorality and even in crime that flaunts its disrespect for the law [...] Abjection, on the other hand, is immoral, sinister, scheming, and shady: a terror that dissembles, a hatred that smiles, a passion that uses the body for barter instead of inflaming it, a debtor who sells you up, a friend who stabs you [...] (4)

No se quiere proponer aquí que la función de la naturaleza en La charca corresponda con un modelo de conducta moral para la sociedad, puesto que la naturaleza misma es amoral (no tiene libre albedrío y por eso no puede escoger entre el bien y el mal; no ISSN 0034-9631 (Impreso) ISSN 2154-4794 (Electrónico) 
toma partido); su función consiste en amplificar aún más el contraste entre su pureza y la depravación del ser humano. A causa de su falta de libre albedrío, la naturaleza coincide con un ser eterno y a veces, mediante su empatía, sirve de testigo a los males de la sociedad puertorriqueña sin nunca llegar a defender a los infelices. Recoge los sufrimientos de los seres vivientes y, mudamente, los lleva consigo en su perpetuo ciclo vital, conservándolos secretamente. Es una entidad incapaz de redimir de manera activa directa los pecados del hombre; puede sólo recordar la presencia de Dios a quien quiera abrir los ojos para verlo y anunciar la posibilidad de redención a quien tenga la voluntad de salvarse. Véase por ejemplo, la personificación del río:

Creyérase que era el río un ser viviente con un pasado escondido en las serranías; con un presente inconforme al recorrer la sinuosa cuenca; con incierto mañana, en el cual, turbio por los arrastres, colmado de impurezas de la tierra, debía precipitarse en el adulto reservorio del mar.

Era un sempiterno quejumbroso; un ser palpitante contemplando con miradas cristalinas el dolor ribereño; un viajero infatigable que, testigo de ese dolor, no tenía ni voz ni palabras para revelarlo a lo porvenir cuando se precipitara en el océano del tiempo. Vivía, vivía entre ambientes de frescura, sobre lechos de cristal, arrastrando sus rumores el haz de lamentos caídos en la corriente, formando con su murmullo la amarga síntesis de un dolor sentido por una multitud de corazones... (256)

Se han dedicado varios estudios al análisis de la naturaleza. Efraín Barradas subraya las diferencias estilísticas en las descripciones del ambiente natural, que adquieren tonos más líricos y, según él, modernistas. Al contrario, la manera de dibujar a los seres humanos de Zeno Gandía sigue un estilo naturalista, aunque no de los más objetivos. También se ha visto a la naturaleza como un ser indiferente y se ha tratado de explicar el por qué de esta actitud. Ernesto Álvarez propone que el naturalismo percibía la naturaleza en términos de determinismo ambiental, o sea que de alguna manera el medio ambiente influenciaba y marcaba la conducta moral del ser humano, justificando sus acciones inmorales. Según Álvarez, la indiferencia de la naturaleza en La charca simboliza un distanciamiento de Zeno Gandía de la corriente naturalista y, a la vez, tendría la función de obligar al ser humano a hacerse responsable de sus acciones. Además, Álvarez desafía la misma idea de la impasibilidad de la naturaleza:

Han extrañado los críticos de Zeno Gandía el que siempre, tras los más viles acto de sus perversos personajes, ocurra un canto lírico a la naturaleza y se contentan con inducir que hay contraste en la descripción entre el hecho del hombre y la indiferencia de la naturaleza. No es esto indiferencia. El autor quiere demostrar la no culpabilidad, la inocencia de ella. (175)

Parece ser entonces que la naturaleza en La charca oscila entre impotencia y empatía. ISSN 0034-9631 (Impreso)

Vol. LXXIX, Núms. 244-245, Julio-Diciembre 2013, 797-816 ISSN 2154-4794 (Electrónico)
En las escenas en que aparece más indiferente hacia el ser humano, su indolencia tiene una doble función. Por un lado, como menciona Álvarez, muestra su pureza y falta de responsabilidad sobre la conducta humana. Por el otro, mediante su incorruptibilidad, recuerda al hombre que ambos vienen del mismo principio creador y por lo tanto, el ser humano puede escoger abandonar su vida abyecta y volver a lo sagrado. Entonces, lo que muchos críticos han visto como frialdad coincide más bien con su amoralidad $\mathrm{y}$, consecuentemente, con su incapacidad de incidir sobre la conducta de los seres vivientes para ayudarlos a salvarse. Al mismo tiempo, en la novela se halla otra cara de la naturaleza que es producto de su empatía hacia el género humano. A menudo acompaña las vicisitudes de los protagonistas: "La canción de Gines se desdoblaba en el monte en cien resonancias: brotaba alegre, festiva, sonora, y la repetían las concavidades de la montaña, melancólica, triste, indecisa..." (63). La naturaleza muestra su solidaridad con la desgracia de Ginés y parece profetizar su muerte, como si su eternidad la pusiera en una posición privilegiada de testigo impotente de los eventos que seguirán ese canto. Otro ejemplo de esta sensación ocurre cuando, la noche en que Galante viola a Silvina, una lluvia torrencial acompaña los acontecimientos. El lado empático de la naturaleza se revela en una especie de sentimiento de hermandad entre ella y el ser humano, por ser ambos creaciones del mismo demiurgo.

A menudo en el texto se insinúa la existencia de una entidad divina detrás de la naturaleza: "Los colores bullían como chispas de luz, confundiéndose en tintas intermedias, interrumpiéndose con alegres contrastes. Diríase que con aquel reguero de colores, eran los campos la inmensa paleta en donde había de humedecer sus pinceles el supremo artista" (38). La presencia de un demiurgo se refleja en su creación más incontaminada, la naturaleza que, por falta de libre albedrío, no se ha corrompido y ha mantenido sus características más divinas. De tal manera, la isla de Puerto Rico parece un "paraíso bíblico", cuyo medio ambiente lozano y virgen, produce frutos eterna e incesantemente. La vida del mundo natural se rige por ciclos, el del sembrado, de la germinación, de la cosecha, del día, de la noche, de la vida y de la muerte, en un infinito movimiento independiente cuyo motor es su divino creador:

La noche [se] deslizaba lentamente con la precisión de su eterno ciclo, a compás de sus rumores peculiares e iluminada por indecisa luz descendida desde el azul con la tenuidad de un beso tímido y con el misterio de un amor furtivo. Algunas luciérnagas trazaban en el vacío los zigzags de su suelo luminoso o determinaban, deteniéndose en los arbustos, puntos brillantes que parecían ojuelos de hadas o lentejuelas adornando las vestiduras de la tierra. La naturaleza dormitaba entregada a sí misma sin que en el volteo de sus horas recibiera impulso de la mano del hombre y sola, moviéndose bajo el empuje del divino soplo, reinaba magnífica, sorprendente, como soberana del mundo, como hija de la eternidad, como madre bienhechora de los humanos destinos. (60)

Revista Iberoamericana, Vol. LXXIX, Núms. 244-245, Julio-Diciembre 2013, 797-816 ISSN 0034-9631 (Impreso) ISSN 2154-4794 (Electrónico) 
Los aspectos sagrados de la naturaleza corresponden a esta perpetuidad, basada en los ciclos constantes de vida y de muerte, a su pureza, ejemplificada por su carácter salvaje y virgen, y a su poderosa productividad. Para resumir, la naturaleza encierra el enigma del origen, impenetrable para los seres vivientes de esta comunidad. La existencia de este misterio denota la falta de comunión entre el mundo natural y la gente del pueblo, que se convierten en dos entidades separadas, incapaces de comunicarse el uno con la otra. De la misma manera en que la naturaleza se encuentra impotente frente a la inmoralidad del hombre, éste no consigue ver la pureza de lo natural y la única interacción que tiene con ella es la de sacar provecho explotándola en los cafetales.

Sin embargo, para dos de los protagonistas de La charca, la naturaleza no pasa completamente inobservada; me refiero a Silvina y Marcelo, las víctimas de la novela. A mirar el ambiente natural que los rodea, ambos se quedan aturdidos o experimentan un estado de éxtasis: "Desde allí [Ciro] divisó a Marcelo, retraído en el umbral y mirando con aire abobado las ramas de un árbol" (113). Algo parecido le pasa a menudo a Silvina: "Y mientras Gaspar, reacio, discutía, Silvina, entregada de nuevo al éxtasis, veía cómo en el cielo íbase apagando el día y cómo las sombras iban lentamente arropando los contornos" (47). Los jóvenes no llegan a entender el misterio de la naturaleza, sino sólo a percibirlo de manera inconsciente; esto ocurre a causa de su vulnerable sensibilidad. Su ignorancia y su costumbre de vivir una realidad abyecta no les permite trascender el mundo vicioso en que viven y en el cual se quedan entonces atrapados. Rudolf Otto en su libro The Idea of the Holy expresa el primordial sentimiento de percepción de lo divino en términos del "misterio tremendo": "Even on the lowest level of religious development the essential characteristic [...] lies rather, we repeat, in a particular 'moment' of consciousness, to wit, the stupor before something 'wholly other', whether such an other be named 'spirit' or 'daemon' or 'deva' or be left without any name" (27). En el caso de Silvina y Marcelo, nunca se llega a un momento de verdadera toma de conciencia de esta "otredad"; ellos sienten el estupor, pero no reconocen ninguna entidad sagrada como la causa de este éxtasis: "En el acerbo de su existencia no tuvo más consuelo que la soledad de las selvas, el correr por veredas solitarias, el extasiarse contemplando, sin sentirlo ni comprenderlo, el bravío panorama de la comarca [...]" (44). El paisaje ofrece entonces una vía de escape de la realidad o por lo menos, constituye un refugio mental.

En varias ocasiones Silvina busca la protección de la naturaleza. Por ser esclava sexual de Galante y Gaspar y, al mismo tiempo, medio de intercambio de su madre Leandra, la chica va progresivamente desposeyéndose de su alma y de su cuerpo. Mediante los siempre más frecuentes ataques epilépticos, Silvina experimenta estados de trance durante los cuales pierde completamente el contacto con el mundo exterior:

Así caminó algunos metros. Detúvose de pronto. La había invadido un aura vaga, algo inexplicable. Sintió extraño aturdimiento, hebetud profunda. Fijó la mirada en un

Revista Iberoamericana, Vol. LXXIX, Núms. 244-245, Julio-Diciembre 2013, 797-816 ISSN 0034-9631 (Impreso) ISSN 2154-4794 (Electrónico) punto del espacio, $\mathrm{y}$, dando algunos pasos rápidos, se sujeto de un árbol, abrazándose al tronco. Luego perdió la noción del mundo. En su torno desvaneciéronse las cosas, la ideación conciente interrumpió su enlace, dejó de saber en dónde estaba, en su cerebro nada existía, ni pasado, ni presente, y al fin, cayendo en una absoluta privación de la vida cerebral, se tambaleó en vértigo idiota. (131)

Álvarez nota que en este episodio, Silvina se agarra a los árboles de la misma manera en que lo hace al comienzo de la novela, cuando llama a Leandra que esta lavando en el fondo de la vertiente. Silvina entonces, aunque no consiga penetrar los misterios de la naturaleza para descubrir así sus aspectos sagrados, busca su apoyo de manera instintiva. Sin embargo, a causa de su existencia atrapada en un mundo abyecto, los ataques que la afligen la transforman en un organismo vacío y paralizado; ella no consigue sentir su cuerpo y se vuelve una estatua, un títere, "[...] masa inerte que iría donde la llevaran" (175)

La escena final de la novela, la muerte de Silvina, ejemplifica su vuelta final a lo orgánico, al origen y a la pureza. Después de haber sufrido de un ulterior ataque epiléptico, cae en la vertiente. Para enfatizar la metamorfosis de Silvina, que de ser humano se convierte en materia, el autor usa el género masculino, refiriéndose al cuerpo de la joven:

La vertiente, llena de árboles y malezas, abrió camino al cuerpo, doblándose los tallos verdes, entreabriéndose las marañas, quebrándose las hierbas secas, desplazándose los hacinamientos de pajuncias que formaban lecho en el declive.

Caía con la pesadumbre de lo que no ha de levantarse más. Rodaba volteando sobre sí misma, chocaba contra los obstáculos, rebotaba de piedra en piedra, deteníase un punto en el tronco de algún árbol hasta que la pesantez la empujaba de nuevo [...] (258)

Además, nótese la empatía de la naturaleza representada por las piedras que acompañan la caída de la joven. Éstas muestran un inicio de comunión entre el ser humano y el mundo natural, que puede ocurrir sólo con el abandono de lo abyecto mediante la muerte.

[el cuerpo de Silvina] arrastraba en la caída montones de piedras rodadizas que le seguían como si aquellas piedras, más piadosas que los hombres, quisieran, en fúnebre cortejo, acompañarle hasta el fondo.

Despeñábase dejando rastro sangriento, un surco rojo. Era la vida volviendo a su origen, los alientos prestados reintegrándose a la tierra, la materia devolviendo sus despojos a la gran cuna común. (258)

Como confirmación de esta hipótesis, hay que notar que el cuerpo de Silvina cae precisamente en frente de su madre, sobre la piedra en que ésta lava la ropa.

Revista Iberoamericana, Vol. LXXIX, Núms. 244-245, Julio-Diciembre 2013, 797-816 
Así, malherida, con los huesos rotos, desfigurada, llena de sangre, muerta en e despeñadero antes que en el paroxismo, Silvina cayó como masa informe sobre la piedra lisa y plana en que lavaba Leandra.

[...] Así estaba mutilada, inerte, la hija a los pies de la madre, la hechura junto al artífice, el jirón junto al andrajo, el engendro junto al materno claustro, en donde con inconsciente bestialidad la formara el acaso. (259)

Sólo una vez que Silvina ha muerto sentimos finalmente la presencia de Dios: "En el misterio de la noche, Dios sollozaba" (259). Aparece por fin, la divinidad que ha estado ausente entre los hombres durante toda la novela. ¿Llorará Dios porque únicamente después de haber muerto Silvina, se reúne ella con la naturaleza y, por consecuencia con lo sagrado? ¿Podría representar este llanto de Dios su tristeza por la incapacidad del hombre de escoger un camino moral y redimirse mientras todavía vive? ¿Solloza Dios a causa del fracaso de su propia criatura?

Con este dramático final, Zeno Gandía indica que la comunión entre el ser humano y la naturaleza es la única vía de escape de la corrupción moral que domina a los isleños Mediante la contraposición entre la sociedad puertorriqueña afligida por los siete pecados capitales y la sacralidad de la naturaleza, Zeno Gandía lleva a cabo su propósito de denunciar la inmoralidad de su país. Sin una vuelta al origen y a la pureza, no hay redención en el mundo humano, no hay posibilidad de mejorarse, avanzar socialmente, o liberarse de los explotadores.

\section{OBRAS CITADAS}

Alegría, Fernando. Nueva historia de la novela hispanoamericana. Hanover: Ediciones del Norte, 1986.

Algarín, Pedro José. "El naturalismo en ManuelZeno Gandía”. Tesis doctoral. University of Illinois at Urbana Champaign, 1972.

Álvarez, Ernesto. Manuel Zeno Gandía: estética y sociedad. Río Piedras: Editorial de la Universidad de Puerto Rico, 1987.

Ara, Guillermo. La novela naturalista hispanoamericana. Buenos Aires: Editorial Universitaria, 1965.

Barradas, Efraín. "La naturaleza en La charca: tema y estilo". Sin Nombre 5/1 (1974) 30-42.

Beauchamp, José Juan. Imagen del puertorriqueño en la novela: en Alejandro Tapia y Rivera, Manuel Zeno Gandia y Enrique A. Laguerre. Río Piedras: Universidad de Puerto Rico, 1976.

Berg, William J. “A Poetics of Vision: Zola's Theory and Criticism.” Bloom's Modern Critical Views: Emile Zola. Harold Bloom, introducción y edición. Philadelphia: Chelsea House Publishers, 2004. 37-69. ISSN 0034-9631 (Impreso)

ISSN 2154-4794 (Electrónico)
Borie, Jean. Zola et les mythes ou de la nauseé au salut. Paris: Éditions du Seuil, 1871. Calasso, Roberto. La letteratura e gli dei. Milano: Adelphi, 2001.

Carrasquillo Hernández, Tania. "La charca (1894) y la consagración del subalterno puertorriqueño: una mirada desde el siglo XXI al naturalismo de Manuel Zeno Gandía". Au Naturel: (Re)Reading Hispanic Naturalism. J.P. Spicer-Escalantey Lara Anderson, eds. Newcastle upon Tyne: Cambridge Scholars Publishing, 2010. 77-94

Cole, Peter. The Dream of the Poem: Hebrew Poetry from Muslim and Christian Spain 950-1492. Princeton: Princeton UP, 2007.

Colin, René-Pierre. Zola renégats et alliés. La République naturaliste. Lyon: Presses Universitaires de Lyon, 1988.

Cymerman, Claude. "Zola, Cambaceres y las cuestiones de verdad moral y utilidad.” $A u$ Naturel: (Re)Reading Hispanic Naturalism. J.P. Spicer-Escalante y Lara Anderson, ed. Newcastle upon Tyne: Cambridge Scholars Publishing, 2010. 39-58.

Duch, Lluís. "El mito y su definición”. Mito, interpretación y cultura. Francesca Babí i Poca y Domingo Cía Lamana, trads. Barcelona: Herder, 1998. 44-89.

Franco, Jean. Historia la literatura hispanoamericanas. A partir de la Independencia. Barcelona: Editorial Ariel, 2002.

Galimberti, Umberto. I vizi capitali e i nuovi vizi. Milano: Feltrinelli, 2006.

Gardón Franceschi, Margarita. Manuel Zeno Gandía: vida y poesía. San Juan: Editorial Coquí, 1969.

González, Aníbal. "La caída de Silvina: naturalismo y ética de la escritura en la charca (1894) de Manuel Zeno Gandía". Abusos y admoniciones. Ética y escritura en la narrativa hispanoamericana moderna. México: Siglo veintiuno editores, 2001. 70-97.

"Manuel Zeno Gandía (1855-1930)". Latin American Writers. Carlos A. Solé, ed. Vol. 3. New York: Charles Scribner's Sons, 1989. 321-326.

"Turbulencias en La charca: de Lucrecio a Manuel Zeno Gandía". MLN 98/2: 208-22.

GonzálezEchevarría, Roberto. Myth and Archive: A Theory of Latin American Narrative. Cambridge: Cambridhe UP, 1990.

Guillemin, Henri. Zola, légende ou vérité? Paris: René Julliard, 1960.

Guzmán, Julia María. “Realismo ynaturalismo en Puerto Rico". Literatura puertorriqueña 21 conferencias. San Juan: Instituto de cultura puertorriqueña, 1969. 149-177.

Hibbs-Lissorgues, Solange. "Laiglesia católica y el naturalismo". Realismoy naturalismo en España en la segunda mitad del siglo XIX. Yvan Lissorgues, ed. Barcelona: Editorial Anthropos, 1988.

Kristeva, Julia. Powers of Horror. An Essay on Abjection. New York: Columbia UP, 1982 López, Mariano. "El perfil humano de La charca". Sin Nombre 9/4 (1979): 46-61.
Revista Iberoamericana, Vol. LXXIX, Núms. 244-245, Julio-Diciembre 2013, 797-816 ISSN 0034-9631 (Impreso) 
Mitterand, Henri. “Zola, ce rêveur définitif." Bloom 's Modern Critical Views: Émile Zola. Harold Bloom, ed. e intro. Philadelphia: Chelsea House Publishers, 2004. 243-258. Molina Martínez, José Luis. "La literatura anticlerical en el naturalismo". Anticlericalismo y literatura en el siglo XIX. Murcia: Universidad de Murcia, 1998. 263-278.

Otto, Rodolf. The Idea of the Holy. John W. Harvey, trad. London: UP Oxford, 1928. Ouvrard, Pierre. Zola et le prêtre. Préface de Henri Mitterand. Paris: Beauchesne, 1986. Oviedo, José Miguel. Historia de la literatura hispanoamericana. Vol. 2. Del Romanticismo al Modernismo. Madrid: Alianza Editorial, 1997.

Pardo Bazán, Emilia. La cuestión palpitante. José Manuel González Herrán, ed. Barcelona: Anthropos/Universidad de Santiago de Compostela, 1989.

Prendes, Manuel. La novela naturalista hispanoamericana: evolución y direcciones de un proceso narrativo. Madrid: Cátedra, 2003.

Rivera de Álvarez, Josefina. "Zeno Gandía, Manuel (1855-1930)". Diccionario de literatura puertorriqueña. Vol. II. San Juan: Instituto de cultura puertorriqueña, 1974. 1631-38.

Sánchez de Silva, Arlyn. La novelística de Manuel Zeno Gandía. San Juan: Instituto de cultura puertorriqueña, 1996.

Savater, Fernando. Los siete pecados capitales. Barcelona: Debolsillo, 2007.

Savile, Anthony. "Naturalism and the Aesthetic". Bloom 's Modern Critical Views: Émile Zola. Ed. and Intro. by Harold Bloom. Philadelphia: Chelsea House Publishers, 2004. 221-241.

Schimmel, Solomon. The Seven Deadly Sins. Jewish, Christian, and Classical Reflections on Human Nature. New York: The Free Press, 1992.

Serres, Michael. "Language and Space: from Oedipus to Zola." Hermes. Literature, Science, Philosophy. Josué V. Harari y David F. Bell, eds. Baltimore: Johns Hopkins UP, 1982. 39-53.

Sotelo Vázquez, Adolfo. El naturalismo en España: crítica y novela. Salamanca: Ediciones Almar, 2002.

Zeno de Matos, Elena. Manuel Zeno Gandía: documentos biográficos y críticos. San Juan: Copyright Elena Zeno de Matos, 1955.

Zeno Gandía, Manuel. La charca. Río Piedras: Ediciones Huracán, 1999. Poesías. Margarita Gardón Franceschi, ed. San Juan: Editorial Coquí, 1969. Redentores. Aníbal González, ed. San Juan: La Editorial, Universidad de Puerto Rico, 2010.

Zola, Émile. El naturalismo. Jaume Fuster, trad. Selección, introducción y notas de Laureano Bonet. Barcelona: Ediciones Península, 1972. Le roman expérimental. Paris: G. Charpentier Éditeur, 1880. The Experimental Novel and Other Essays Novel. Bellee M. Sherman, trad. New York: Haskell House, 1964.

Revista Iberoamericana, Vol. LXXIX, Núms. 244-245, Julio-Diciembre 2013, 797-816 